\title{
Structural modelling of Automotive Engine Mounting from Kenaf fibre reinforced natural rubber/thermoplastic polyurethane "Green" Composites
}

\author{
A.M. Noor Azammi, S.M. Sapuan, Mohamed T.H. Sultan, \\ Mohamad R. Ishak
}

\begin{abstract}
This paper presents an investigation of deformation analysis using ANSYS of automotive engine rubber mount made from kenaf fiber reinforced natural rubber (NR)/thermoplastic polyurethane (TPU) composites. The modelling of mounting was conducted using CATIA software. To determine the of the Poisson's ratio of this new material composites is important, which was required data to be filled into the ANSYS software. The Poisson's ratio was calculated based on the previous data experiment from the stress-strain results. The analysis was focussing on the deformation and stress analysis effected from the pressure that was applied in the modelling and in the ANSYS simulation software which is 250 psi. The deformation and stress simulation results were then identified and discussed and the results were compared to the Natural Rubber material of the same design simulation.
\end{abstract}

Keyword: Structural Analysis, Kenaf Fiber TPU Composites, Engine Rubber Mounting, ANSYS

\section{INTRODUCTION}

An automotive engine mount is a part that holds the engine in a car. In a typical car, the engine and transmission are bolted together and held in place by three or four mounts. An engine mount is made of rubber and steel. It has two purposes; to secure the engine and transmission to the frame of the car, and to absorb the road shocks and engine vibrations so that the driver does not feel any engine movement. There is also the transmission mount that secures the transmission.

Natural rubber was generally used in mountings because of its combination of properties. Natural rubber provides high strength, outstanding fatigue resistance, high resilience, low sensitivity to strain effects in dynamic applications and good resistance to creep [1]. In the real condition of the engine rubber mount other than absorbing vibration, the mounting also exposes to heat and chemical spills. The heat generated from the engine itself, near to exhaust manifold and sometime

Revised Manuscript Received on July 05, 2019.

S. M. Sapuan, Advanced Engineering Materials and Composite Research Centre, Department of Mechanical and Manufacturing Engineering, University Putra Malaysia, 43400 Serdang, Selangor, Malaysia. Corresponding author.Email:sapuan@upm.edu.my

.Mohamed T. H. Sultan, Laboratory of Biocomposite Technology, Institute of Tropical Forestry and Forest Products (INTROP), Universiti Putra Malaysia, 43400, UPM Serdang, Selangor, Malaysia.

Mohamad R. Ishak, Department of Aerospace Engineering, Universiti Putra Malaysia, 43400, UPM Serdang, Selangor, Malaysia. spill from brake fluid, coolant, petrol will tend to reduce its lifespan. The engine operating temperature was above $80^{\circ} \mathrm{C}$ and can reach over $100^{\circ} \mathrm{C}$ at the nearest exhaust manifold or catalytic converter. The operation at the high temperature must need to use expensive silicone rubber for the engine mounting. The temperature of the engine mount can increase if the available space for ventilation was decreased [2]. There is some design consideration for engine mounts such as mount configuration and torque axis [3]. Others design approach simplify a multidisciplinary optimization problem by reducing the total number of the design objectives based on the natural character of the engineering structure [4].

The engine compartment in a vehicle is an environment involving heat dissipation from the engine combustion itself, exhaust system and the road condition contribute to heat produced under the hood. In these conditions all component in the engine compartment will be exposed to heat thus will reduce its life span and increase wear and tear of the component. At the same time, the vibration produced by the engine and road condition will create fatigue in most of the component in the engine compartment. Under these circumstances, the engine component such as bearings, rubber seals, hose connectors, rubber mountings will come to its failure much faster. Figure 1 shows the comparison of a good condition and a failure condition of automotive engine rubber mounting. Figure 2 shows the force direction of the applied pressure in the modelling.

In this ANSYS simulation, only two axes forced were determined which is $\mathrm{x}$-axis forced and $\mathrm{y}$-axis forced. The $\mathrm{x}$-axis forced was related to the weight of the engine and the power transmission. Both of the components weighing between 200 to $300 \mathrm{~kg}$ and it depends on the capacity if the engine. The y-axis is related to the lateral weight shift [5] which also related to the weight of the engine and power transmission. Traditionally rubber is the best material to handle the impact load from the engine and power transmission beside material cost which is more economical than other material.

Another material which related to the fiber composites which could be considered to replace rubber such as thermoplastic polyurethane has been amplified with the use of Jute and flax [6], coir palms [4-7], rice husk [11], wood core [12] and sisal [13]. Thermoplastic polyurethane may also be mixed with the

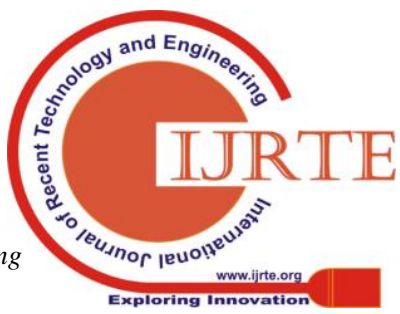


use of fibreglass [14], synthetics such as aramid [15] and carbon fibre [16]. TPU and kenaf fibre mixing was done in the laboratory in UPM. The size of kenaf fibre $125 \mu \mathrm{m}-$ $300 \mu \mathrm{m}$ is selected base on a study by [17] and [18]. The kenaf fiber is treated using $\mathrm{NaOH}$ to increase the crystalline regions for a more stable and rigid structure where the crystallinity index of kenaf is similar to sugar palm nano-fibrillated cellulose (SPNFC) [1].

Poisson's ratio is defined as the ratio of the change in the width per unit width of a material, to the change in its length per unit length, as a result of strain. When a sample of material is stretched in one direction it tends to get thinner in the lateral direction - and if a sample is compressed in one direction it tends to get thicker in the lateral direction [19]. Every each material has its own Poisson ratio and when every new blended material such as natural fiber composite with hybrid composite or fiber, will have a different Poisson ratio number. For example, a study on woven glass fiber layer composite with Poisson ratio is 0.2 [20], epoxidised woven fiber, 0.3 [21] and interlaminar fiber arrangement [22].

In this study, the main focus is to obtain the Poisson's ratio for the new polymer composites from the previous tensile specimens. Then the specific Poisson's ratio value is then used for the ANSYS simulation to analyze the new material composites reliability compared to the existing engine rubber mount. The analysis is conducted using ANSYS simulation which the new material composite will be simulated based on the related axis forced. The deformation and stress occurred in the simulation were analyzed and compared with engine rubber mount.

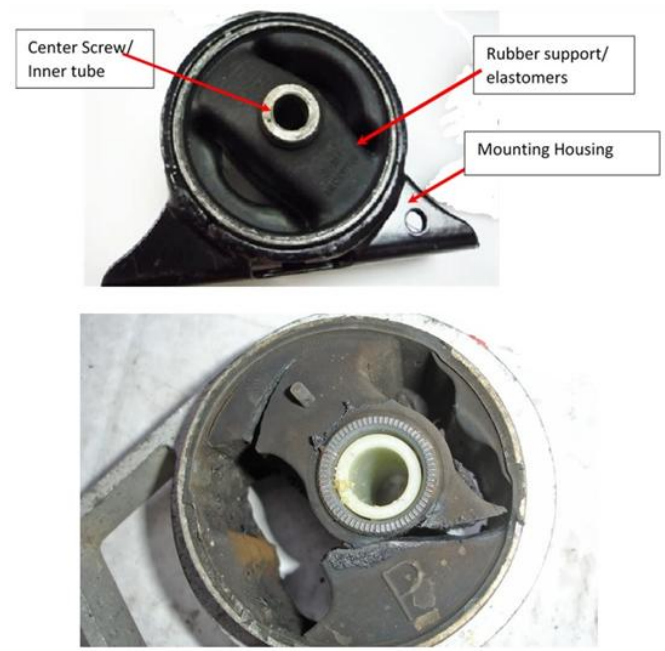

Figure 1: Engine mounting and broken engine mounting

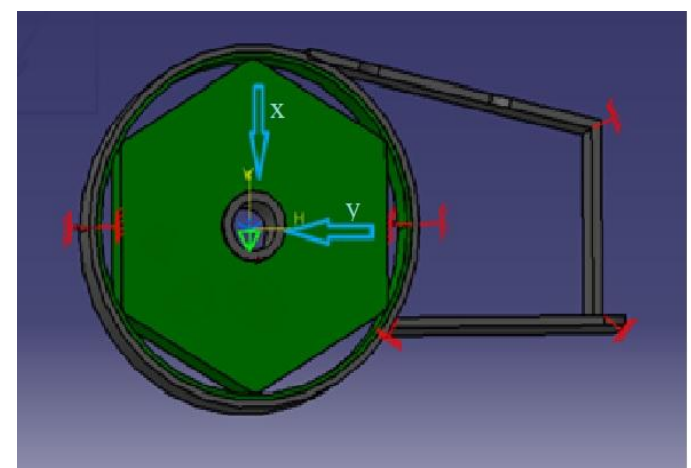

Figure 2: Force direction that is applied in the modelling

\section{METHODOLOGY}

The early stage of engine rubber mounting design has been conducted from the previous study. From the stage of the design proposal, design specification and lastly design selection has successfully conducted.

\section{A. Process of Design Simulation}

From the previous study on conceptual design selection work which has been done using the TRIZ method, morphological and ANP selection method, conceptual design no 3 has been selected [23]. Next stage is to analyse the structural strength of the engine rubber mounting composites using finite element analysis. In this analysis, ANSYS has been chosen to do the stress-strain and the deformation effect.

Before proceeding to the analysis, the selected conceptual design must be validated through the $2 \mathrm{D}$ and isometric drawing using CATIA software before the drawing is converted into a $3 \mathrm{D}$ drawing design. Figures show the process of changing isometric drawing into the solid 3D design.

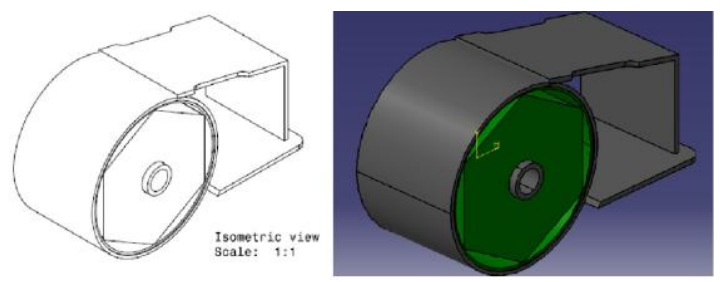

Figure 3: Final design of the Autocad and 3D design

Next is to insert the material data specification which is the material properties or characterization has been conducted in the lab experiment [24], [25]. In this analysis, two types of material are selected to make a comparison between natural rubber and $\mathrm{KF}+\mathrm{TPU}+\mathrm{NR}$. This comparison is to investigate side by side on the stress-strain and the deformation analysis. The material properties of both materials are shown in Table 1. The rubber material properties are achieved from the ANSYS materials library list.

In this section, all the data gathered from the previous work [24], [25] are compiled and tabled according to the required data by the ANSYS software and CATIA software.

\section{B. Determination of Poisson's Ratio}

Tensile test result from the previous study was used to measure the length and width changes of the specimens. The changes of length of the specimens are carefully measured using digital vernier calliper while the width changes are measured using a digital micrometre gauge. With this measurement, the Poisson's ratio can be determined by applying these few formulas as follows:

$$
\begin{aligned}
& \mu=\frac{\varepsilon t}{\varepsilon l} \\
& \text { Where } \\
& \mu=\text { Poisson's ratio } \\
& \varepsilon t=\text { transverse strain } \\
& \varepsilon l=\text { longitudinal strain }
\end{aligned}
$$

Published By:

Blue Eyes Intelligence Engineering

\& Sciences Publication 
Longitudinal Strain can be expressed as;

$\varepsilon l=\Delta \mathrm{l} / \mathrm{L}$

where

$\Delta \mathrm{l}=$ change in length

$\mathrm{L}=$ initial length

Transverse Strain can be expressed as;

$$
\varepsilon t=\Delta \mathrm{t} / \mathrm{T}
$$

$$
\begin{aligned}
& \text { Where } \\
& \Delta \mathrm{t}=\text { change of width } \\
& \mathrm{T}=\text { initial width }
\end{aligned}
$$

Once the Poisson's ratio was achieved, it was used in the ANSYS simulation software to identify the deformation engine mounting

\section{Determination of Force}

The direction or axis has been determined which is related to $\mathrm{x}$-axis and $\mathrm{y}$-axis of the polymer composite engine mounting from the drawing design in Figure 2. To give a fair force value between natural rubber and polymer composite, the same force value that is tested for the natural rubber is used for the polymer composites for the force value.

At the engine rubber mount components, there are always several axis force that is involved such as the $\mathrm{x}$-axis force, $\mathrm{y}$-axis force, $\mathrm{z}$-axis force and there is torsional axis force involved in an engine mounting system. This force axis has its own limited force according to the manufacturer specification. In this case, the new testing for a new material that is used to simulate must use the default force axis value which 250 psi for every each axis force. It is reported that the generally accepted limit in compression is about 250 psi but Torsional force is not involved in this study. Next step is to use the intended force value that is suitable for the polymer composite and natural rubber to be simulated using ANSYS. With the simulation conduct, the deformation and stress

\section{RESULT AND DISCUSSION}

\section{A. Poisson's Ratio of Polymer Composites}

Based on the length and width changes in the tensile specimens in Figure 4, the measured data is compiled and ready to be applied in the equation (1), (2) and (3). There two specimens that are chosen involved in this study.

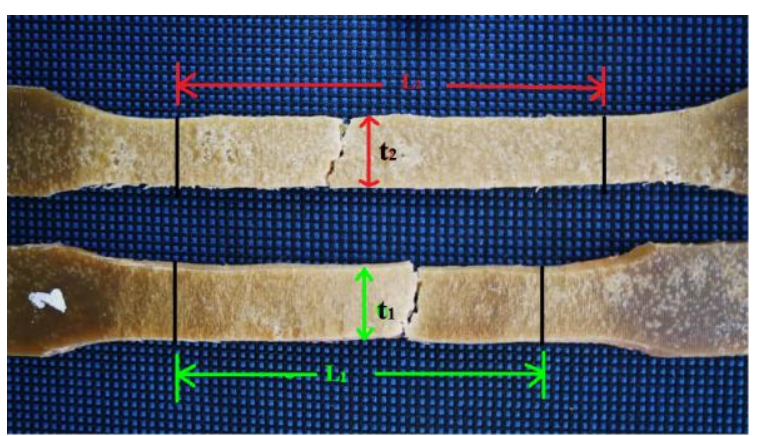

Figure 4: Tensile specimens effect and the strain occurred at the polymer composite stresses as high as 500 psi is used to test new material [2]. result were analysed.

The standard value for

$$
\begin{aligned}
& \mathrm{L}=57 \mathrm{~mm} \\
& \mathrm{~T}=13 \mathrm{~mm} \\
& \Delta \mathrm{l}=\mathrm{L}_{1} \text { and } \mathrm{L}_{2}-\mathrm{L} \\
& \Delta \mathrm{t}=\mathrm{T}-\mathrm{t}_{1} \text { and } \mathrm{t}_{2}
\end{aligned}
$$

Table 1: Dimension properties of the tensile specimens

\begin{tabular}{|l|l|l|l|l|l|l|c|c|c|}
\hline & $\mathrm{L}$ & $\mathrm{T}$ & $\mathrm{L}_{\mathrm{X}}$ & $\mathrm{T}_{\mathrm{X}}$ & $\Delta \mathrm{l}$ & $\Delta \mathrm{t}$ & $\varepsilon l$ & $\varepsilon t$ & $\mu$ \\
\hline Sample1 & 57 & 13 & 65.68 & 12.14 & 8.68 & 0.86 & 0.15228 & 0.06615 & 0.4344 \\
\hline Sample2 & 57 & 13 & 68.25 & 11.86 & 11.25 & 1.14 & 0.19736 & 0.08769 & 0.4430 \\
\hline & & & & & & & & Average & 0.4387 \\
\hline
\end{tabular}

Table 1 shows the Poisson's ratio is nearest to two decimal and 0.44 value is selected. In the next step, all data were tabulated in Table 2, which were in turn used to key in the data into the ANSYS simulation software. The data related to the natural rubber were also included and were in the simulation for the new polymer composites. The natural rubber data were obtained from the library which is included in the ANSYS software.

Table 2: Materials and properties data input in ANSYS

\begin{tabular}{|l|l|l|}
\hline Material & Rubber & KF+TPU+NR \\
\hline Young's Modulus & $2 \mathrm{MPa}$ & $0.85 \mathrm{MPa}$ \\
\hline Poisson's ratio & 0.49 & 0.44 \\
\hline Density & $910 \mathrm{kgm}^{3}$ & $1185.18 \mathrm{kgm}^{3}$ \\
\hline
\end{tabular}

\section{B. Stress Effect due to $\mathbf{2 5 0}$ psi pressure for Natural Rubber and TPU composites}

The ANSYS simulation had been conducted smoothly for both natural rubber and the new polymer composite for the stress analysis. From Figure 5, it is clearly shown that the natural rubber has occurred less stress than the new polymer composites. The highest stress value obtained by natural rubber is $2.1 \mathrm{MPa}$ and $2.8 \mathrm{MPa}$ by the new polymer composites. The affected stress area comparison between natural rubber and the new polymer composites has an almost similar location but the new polymer composites have a much larger effected stress area. This shows the TPU polymer composites leading to the formation of the softer blend which decreases the tensile strength [26]. Although the TPU polymer composites blend is not perfectly miscible but the affected stress region in the ANSYS simulation is double the size of the NR maximum stress.
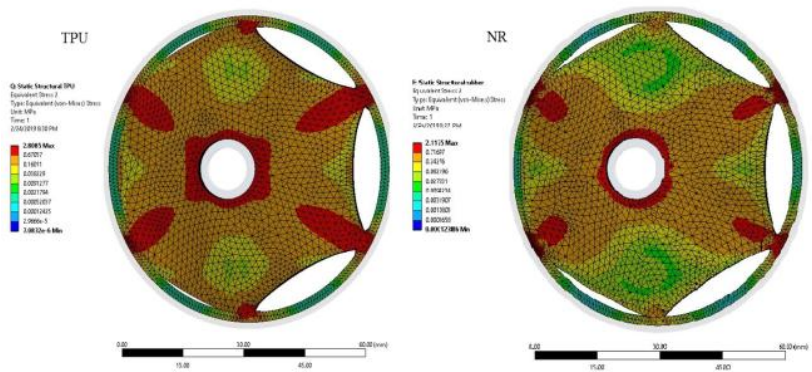

Figure 5: Stress analysis of $\mathrm{x}$-axis and $\mathrm{y}$-axis with 250psi force

Since rubber has higher modulus young compared the 
polymer composites, the elastic ability of the natural rubber give better resistant to the force that is applied to the structure. Although the polymer composites have lower modulus young, the ability of the material to resist the force existed but not as high as natural rubber.

In Figure 6, the simulation result shows less stress region for the natural rubber compared to the polymer composites due to the difference of density. The stress affected area for the polymer composites occurred at all corners of the engine mounting design even though the force occurred perpendicular at $\mathrm{x}$-axis and $\mathrm{y}$-axis.
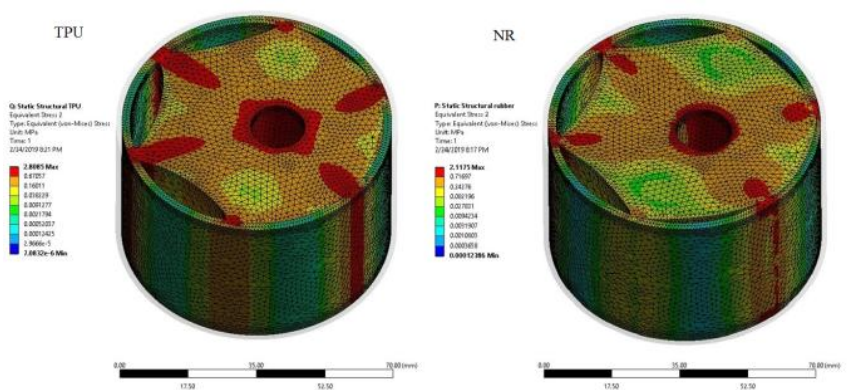

Figure 6: Isometric view of Stress analysis of $\mathrm{x}$-axis and $\mathrm{y}$-axis 250psi force

\section{Deformation Effect due to Force 250 psi for Natural Rubber and TPU composites}

In the deformation simulation result, the polymer composites occurred higher than the natural rubber which is $23.6 \mathrm{~mm}$. The deformation affected natural rubber only half of the polymer composites and only occurred $40 \%$ horizontally of the overall body of the engine mounting design. The polymer composites deformation occurs at the centre of the engine mounting design and equally distributed around the centre hole of the engine mounting.
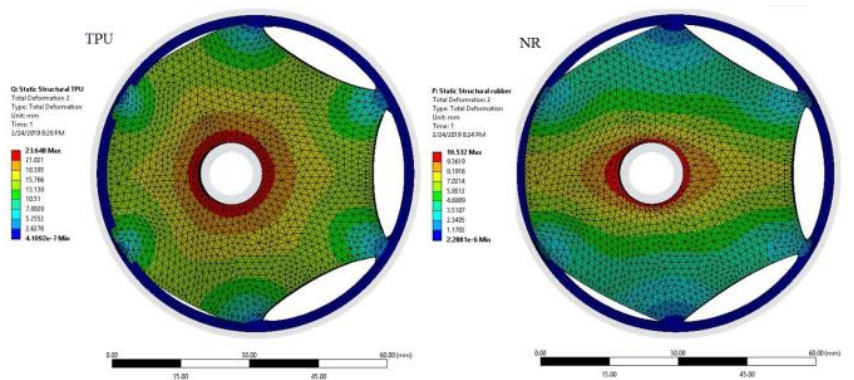

Figure 7: Deformation analysis of 250psi pressure on polymer composites engine mount.

Figure 7 and Figure 8 clearly shows the affected area of deformation in the engine mount that made from polymer composite has a larger area compared to the natural rubber. Although the force direction that is applied at $\mathrm{x}$-axis and $y$-axis, the modulus young of the polymer composites is much lower than natural rubber has caused the affected area became larger. The ability of the natural rubber to resist the force has made this material to return to its original condition thus reduce the deformation area in the engine mounting design. The TPU polymer composites blends show a large area of deformation occurs due to weak bonding crosslink between TPU and NR which resulting in the rise of a large network of the elastic region that contribute to the deformation in the TPU polymer composites simulation [27].

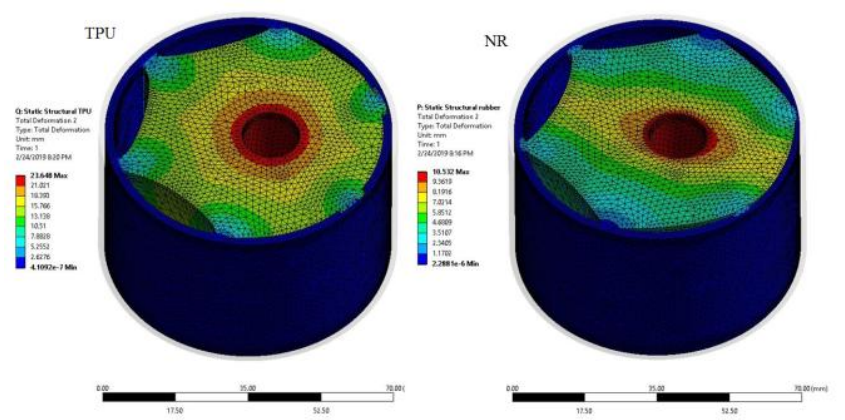

Figure 8: Isometric view of deformation analysis of $250 \mathrm{psi}$ force on the composites engine mount

Table 3: Stress and deformation properties of natural rubber and polymers composites

\begin{tabular}{|l|c|c|}
\hline $\begin{array}{l}\text { Type of composite } \\
\text { for Engine Mount }\end{array}$ & $\begin{array}{c}\text { Stress Max. } \\
\text { (MPa) }\end{array}$ & $\begin{array}{c}\text { Deformation } \\
\text { Max. (mm) }\end{array}$ \\
\hline Natural Rubber (NR) & 2.117 & 10.532 \\
\hline KF+NR+TPU (TPU) & 2.808 & 23.648 \\
\hline
\end{tabular}

From Table 3, there are slight differences in the stress value that occurs for both materials although has large differences in modulus young. The deformation area occurs in the polymer composites are much larger than natural rubber.

\section{CONCLUSIONS}

Both materials (natural rubber and polymers composites) have the ability to deflect the force that is applied in this simulation study. The force of 250 psi from $\mathrm{x}$-axis and $\mathrm{y}$-axis is not able to break the shape and function of the engine mounting for both materials. It means the polymer composites has also the abilities and potential to function as engine rubber mounting. The polymer composites have the content of $75 \%$ of TPU. In future for further investigation, it is recommended to study on increasing the bonding between natural rubber and TPU in the polymer composite which may would improve its modulus young thus improve its stress and deformation to become as an alternative material to replace rubber in the engine mounting.

\section{ACKNOWLEDGMENTS}

The authors would like to thank Universiti Kuala Lumpur (UniKL) and the Ministry of Higher Education Malaysia for providing the scholarship award and financially support through UniKL Grant Scheme (STRG 15144) to the principal author in this project and HiCOE grant (6369107) from Ministry of Higher Education,

Malaysia. 


\section{REFERENCES}

1. J. G. Sommer, "Troubleshooting Rubber Problems," Cincinnati, Ohio: Carl Hanser, 2014, pp. 162-245.

2. J. G. Sommer, "Engineered Rubber Products: Introduction to Design, Manufacturing and Testing," in Engineered Rubber Products: Introduction to Design, Manufacture and Testing, no. Chapter 2, Cincinnati, Ohio: Hanser, 2009, pp. 14-24.

3. A. Adhau and P. V Kumar, "Engine Mounts and its Design Considerations,” Int. J. Eng. Res. Technol., vol. 2, no. 11, pp. 763-769, 2013.

4. Z. Ma and C. Qi, "Multidisciplinary design optimisation of elastomeric mounting systems in automotive vehicles," Int. J. Prod. Dev., vol. 1, no. September, pp. 365-382, 2005.

5. K. Jalali, T. Uchida, S. Lambert, and J. Mcphee, "Development of an Advanced Torque Vectoring Control System for an Electric Vehicle with In-Wheel Motors using Soft Computing Techniques Development of an Advanced Torque Vectoring Control System for an Electric Vehicle with In-wheel Motors using Soft Comp," Soc. Automot. Eng. Int., vol. 2, no. April 2014, pp. 261-278, 2013

6. A. K. Bledzki, W. Zhang, and A. Chate, "Natural-fibre-reinforced polyurethane microfoams," Compos. Sci. Technol., no. 61, pp. 2405-2411, 2001.

7. H. D. Rozman, K. R. Ahmad Hilmi, and A. Abu Bakar, "Polyurethane (PU) - Oil palm empty fruit bunch (EFB) composites: The effect of EFBG reinforcement in mat form and isocyanate treatment on the mechanical properties," Polym. Test., no. 23, pp. 559-565, 2004.

8. H. D. Rozman and G. S. Tay, "The effects of $\mathrm{NCO} / \mathrm{OH}$ ratio on propylene oxide-modified oil palm empty fruit bunch-based polyurethane composites," J. Appl. Polym. Sci., vol. 110, pp. 3647-3654, 2008

9. H. Rozman, G. Tay, A. Abubakar, and R.. Kumar, "Tensile properties of oil palm empty fruit bunch-polyurethane composites," Eur. Polym. J., vol. 37, no. 9, pp. 1759-1765, 2001.

10. [10] K. A. M. Amin and K. H. Badri, "Palm-based bio-composites hybridized with kaolinite," J. Appl. Polym. Sci., vol. 105, pp. 2488-2496, 2007.

11. H. D. Rozman, Y. S. Yeo, G. S. Tay, and A. Abubakar, "The mechanical and physical properties of polyurethane composites based on rice husk and polyethylene glycol," Polym. Test., vol. 22, pp. 617-623, 2003.

12. M. Ozgur Seydibeyoglu and K. Oksman, "Novel nanocomposites based on polyurethane and micro fibrillated cellulose," Compos. Sci. Technol., vol. 68, pp. 908-914, 2008.

13. I. O. Bakare, F. E. Okieimen, C. Pavithran, H. P. S. Abdul Khalil, and M. Brahmakumar, "Mechanical and thermal properties of sisal fiber-reinforced rubber seed oil-based polyurethane composites,' Mater. Des., vol. 31, pp. 4274-4280, 2010.

14. S. Wilberforce and S. Hashemi, "Effect of fibre concentration, strain rate and weldline on mechanical properties of injection-moulded short glass fibre reinforced thermoplastic polyurethane," J. Mater. Sci., no. 44, pp. 1333-1343, 2009.

15. C. Vajrasthira, T. Amornsakchai, and S. Bualek-Limcharoen, "Fiber-matrix interactions in aramid-short-fiber-reinforced thermoplastic polyurethane composites," J. Appl. Polym. Sci., vol. 87, pp. 1059-1067, 2003

16. R. A. Correa, R. C. R. Nunes, and W.Z. Franco Filho, "Short Fiber Reinforced Thermoplastic Polyurethane Elastomer Composites*," Polym. Compos., vol. 19, pp. 152-155, 1998.

17. M. A. Abu Bakar et al., "Characterization of rubber toughened epoxy reinforced hybrid kenaf/carbon fiber via water absorption and thermal degradation," J. Teknol., vol. 76, no. 3, pp. 81-85, 2015

18. Y. A. El-Shekeil, M. S. Salit, K. Abdan, and E. S. Zainudin, "Development of a new kenaf bast fiber-reinforced thermoplastic polyurethane composite," BioResources, vol. 6, pp. 4662-4672, 2011.

19. R. A. Ilyas et al., "Sugar palm (Arenga pinnata (Wurmb.) Merr) cellulosic fibre hierarchy: a comprehensive approach from macro to nano scale," J. Mater. Res. Technol., no. x x, pp. 1-14, 2019

20. Engineering ToolBox, (2008). Poisson's ratio. [online] Available at: https://www.engineeringtoolbox.com/poissons-ratio-d_1224.html [28 April 2019].

21. D. Kim, H. Kim, and H. Kim, "Design optimization and manufacture of hybrid glass/carbon fiber reinforced composite bumper beam for automobile vehicle," Compos. Struct., vol. 131, pp. 742-752, 2015.

22. C. Barschke, Merlin and Pardo, David Alejandro Uribe and Jensen, Jens L and López, "Finite Element Modeling of Composite Materials using Kinematic Constraints," Ing. y Cienc., vol. 5, no. 10, pp. 133-153, 2009
23. L. N. S. Chiu, B. G. Falzon, R. Boman, B. Chen, and W. Yan, "Finite element modelling of composite structures under crushing load," Compos. Struct., vol. 131, pp. 215-228, 2015.

24. A. M. N. Azammi, S. M. Sapuan, M. R. Ishak, and M. T. H. Sultan "Conceptual design of automobile engine rubber mounting composite using TRIZ-Morphological chart-analytic network process technique," Def. Technol., vol. 14, no. 4, 2018.

25. A. M. Noor Azammi, S. M. Sapuan, M. R. Ishak, and M. T. H. Sultan "Mechanical and Thermal Properties of Kenaf Reinforced Thermoplastic Polyurethane (TPU)-Natural Rubber (NR) Composites," Fibers Polym., vol. 19, no. 2, pp. 446-451, 2018.

26. A. M. N. Azammi, S. M. Sapuan, M. R. Ishak, and M. T. H. Sultan, "Mechanical properties of kenaf fibre thermoplastic polyurethane-natural rubber composites," Polimery, vol. 63, no. 7, p. $45,2018$.

27. N. A. Ahad, S. H. Ahmad, and N. M. Zain, "The Compatibility of TPU and NR Blends," Adv. Mater. Res., vol. 879, pp. 107-111, 2014.

28. N. A. Ahad, S. H. Ahmad, and N. M. Zain, "Effects of NR and Liquid NR Loading on Swelling Behaviour of TPU/NR Blends," Adv. Mater. Res., vol. 795, pp. 133-136, 2013.

\section{AUTHORS PROFILE}

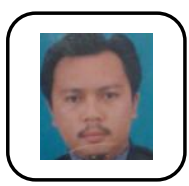

Noor Azammi B. Abdul Murat.

Certificate [PUO], Dip. Mech [PKB], B.Eng (Hons) [UTHM], M.Sc [IIUM]

Area of Interest; Composites, Conceptual Design, Automotive Technology.

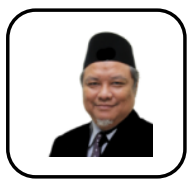

Professor Ir. Dr Mohd Sapuan b. Salit

B.Eng. (Newcastle, Aus.),M.Sc. (Loughborough), Ph.D (DeMontfort, Leicester),

LFIBA, FIMM, FSAE, FPRIM, LMInTeM, P.Eng. , HMAPA, MIAENG, MiNEER, FMSA Areas of interest: Composite Material, Concurrent Engineering

Assoc. Prof. Ir. Ts. Dr. Mohamed Thariq bin Haji Hameed Sultan

Certificate [ILP,KL], Dip Mech [UTM], BEng (Hons) [UTHM], MSc [UPM], PhD [Sheffield,UK]

CEng, MIMechE, PEng, MIEM, MAYRC, AAE MMSSHM, MMSNT, MIScT.

Area of Interest: Structural Health Monitoring (SHM), Damage Detections and Repairs, Low And High-Velocity Impact Studies, Composite Materials.

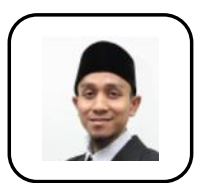

Dr Mohamad Ridzwan Ishak

B.Eng.[UTeM], MSc.[UPM], PhD.[UPM] M.I.E.M., B.P.R.I.M.

Area of Interest: Biocomposite Materials, Manufacturing Process 